\title{
Seed dispersal by Tana River mangabeys in fragmented gallery forests
}

\author{
Duncan M. Kimuyu ${ }^{1 *}$, Geoffrey M. Wahungu ${ }^{1}$, Dennis O. Otieno ${ }^{2}$ \\ ${ }^{1}$ School of Natural Resources and Environmental Studies, Karatina University College, Karatina, Kenya; \\ *Corresponding Author: dkimuyu@gmail.com \\ ${ }^{2}$ Department of Plant Ecology, University of Bayreuth, Bayreuth, Germany
}

Received 28 November 2011; revised 27 December 2011; accepted 10 January 2012

\begin{abstract}
Data collected on a free ranging group of Tana River mangabeys (Cercocebus galeritus) indicates that this endangered primate species, which has previously been regarded as a seed predator, plays an important role in seed dispersal and do contribute to the regeneration of a highly fragmented gallery forest. We observed fruit handling behavior and the post-dispersal fate of seeds ingested by the mangabeys. The two main fruit handling behaviors observed, fruit swallowing and processing fruits in cheek pouches, positively contributed to seed dispersal. Seed predation was not common during this study, apart from a few particular plant species such as Acacia robusta and Alangium salviifolium with non-fleshy fruits. We found a correlation between seed predation and fruit availability, respectively seasonal differential specific dispersal efficiency. The role of the mangabeys in dispersing seeds and facilitating forest regeneration is enhanced by their movement across forest patches through non-forested matrix, which contributes to the deposition of seeds and regeneration in these habitat gaps.
\end{abstract}

Keywords: Cercocebus Galeritus; Seed Dispersal; seed Predation; Seasonality; Dispersal Efficiency; Fragmentation; Habitat Gaps; Tana River Forests

\section{INTRODUCTION}

Forest fragmentation and declining forest cover are matters of global conservation concern. The role of seed dispersers in influencing the distribution of plant species and facilitating the dynamics of forest regeneration is vital [1-5]. However, reliable field data, especially for endangered and endemic seed dispersers, are rare. This is because the understanding of the relative importance of seed dispersers requires local case-to-case studies, as their competitive role in different biocoenosis can vary. Dispersers also differ in diet, digestive anatomy, body size, social structure, and movement patterns [6]. Even for local groups or members of a given species, seasonal variations in food availability may cause great differences in their plant-specific seed dispersal efficiency [68]. Evaluations on the effectiveness of a particular disperser also requires quantification of the fate of dispersed seeds [9].

Among animals, many primates are major seed dispersers [10-12]. They constitute between $25 \%$ to $40 \%$ of frugivore biomass in tropical forests [13]. Primates can be categorized as predominantly frugivorous seed dispersers or much less common granivorous seed predators. However, this dichotomy is rather simplistic, considering that most granivorous seed predators do disperse some seeds [14], and seed dispersers specifically can as well predate on seeds [15]. Based on the kind of diaspore and food availability, primates can switch between being predominantly seed predators to seed dispersers and vice versa $[11,14-16]$.

Tana River mangabey (Cercocebus galeritus) is a medium-sized $(5-10 \mathrm{~kg})$ frugivorous primates, occupying fragmented gallery forests in Tana River, Kenya. The species is highly endangered and endemic to Tana River forests [17]. Major threats facing the mangabeys include habitat destruction and increased forest fragmentation [18]. Although the ecology of the mangabeys is well studied [19-22], information concerning their role as seed dispersers is largely missing, and they have generally been considered seed predators $[23,24]$. The Mangabeys have cheek pouches and a comparatively specialized dentition that allow easy seed eating [23]. However, Tana River mangabeys are reported as being able to effectively disperse Phoenix reclinata seeds, one of their main dietary plants [24]. The mangabeys are known to range widely [25], move across forest fragments [26], and utilize non-forested areas between forest patches $[6,27]$.

In this study, we examined 1) the implications of fruit 
and seed processing behavior by the mangabeys on seed dispersal. We estimated 2) the quality and quantity of seed dispersal via direct observations and fecal analyses and 3 ) the post-dispersal fate of seeds. We 4) also considered seasonal fruit availability and its impact on food choice and seed predation. Further we investigated 5) whether the mangabeys could influence the density of seedlings and species diversity in the areas they repeatedly used as sleeping sites. Finally, we 6) evaluated the potential of the mangabeys to contribute to the regeneration of the fragmented gallery forest by relating their movement patterns with seed deposition in the landscape. In view of the level of fragmentation of Tana River forests and the associated threat to biodiversity in the area, the study aims to support new information for conservation and management of the forests.

\section{METHODS}

\subsection{Study Area}

We conducted the study in two adjacent forest patches, Mchelelo West forest (26-ha) and Guru South forest (45ha), along the west bank of the lower Tana River, Kenya (Figure 1). The two forests are part of the $169 \mathrm{~km}^{2}$ Tana River Primate National Reserve (TRPNR). They are located at $1^{\circ} 11^{\prime} \mathrm{S}, 40^{\circ} 5^{\prime} \mathrm{E}$ and are bordered to the east by Tana River and to the west by a dry savanna woodland. The two forests were once part of a 172-ha of continuous Tana River forest block. A 12-ha section to the north of Mchelelo West was cleared in 1966 and farmed until
1969. An additional 16-ha area to the south of Mchelelo West was cleared and farmed until 1973 [28]. These farms separated Mchelelo West and Guru South to the north and Congolani forests to the south. Since the establishment of the TRPNR in the late 1970s human activities have decreased and Mchelelo West forest has been regenerating from previous disturbances [29].

The forests are characterized by emergent trees $(>30 \mathrm{~m})$ such as Sterculia appendiculata and Acacia robusta, canopy trees $(15 \mathrm{~m})$ such as Pachystela msolo, Ficus sycomorus, Diospyros mespiliformes, and Sorindeia madagascariensis, and, smaller solitary or sub-canopy trees such as Phoenix reclinata and Oncoba spinosa [29,30]. Two groups of the Tana River mangabeys inhabit Mchelelo West and Guru South forests. One group has been habituated and studied on several occasions [19-22] while the other group is not habituated. The two forests are also occupied by other primate species including the Tana River red colobus (Procolobus rufomitratus), Sykes' monkey (Cercopithecus mitis albotorquatus), yellow baboon (Papio cynocephalus cynocephalus), and grivet (Cercopithecus aethiops).

\subsection{Fruit and Seed Handling Behavior}

To examine the implications of fruit and seed handling behavior by the mangabeys on dispersal, we followed the habituated group between $0730 \mathrm{~h}$ to $1830 \mathrm{~h}$ for three consecutive days every week from the third week of December 2007 to the second week of April 2008. For six

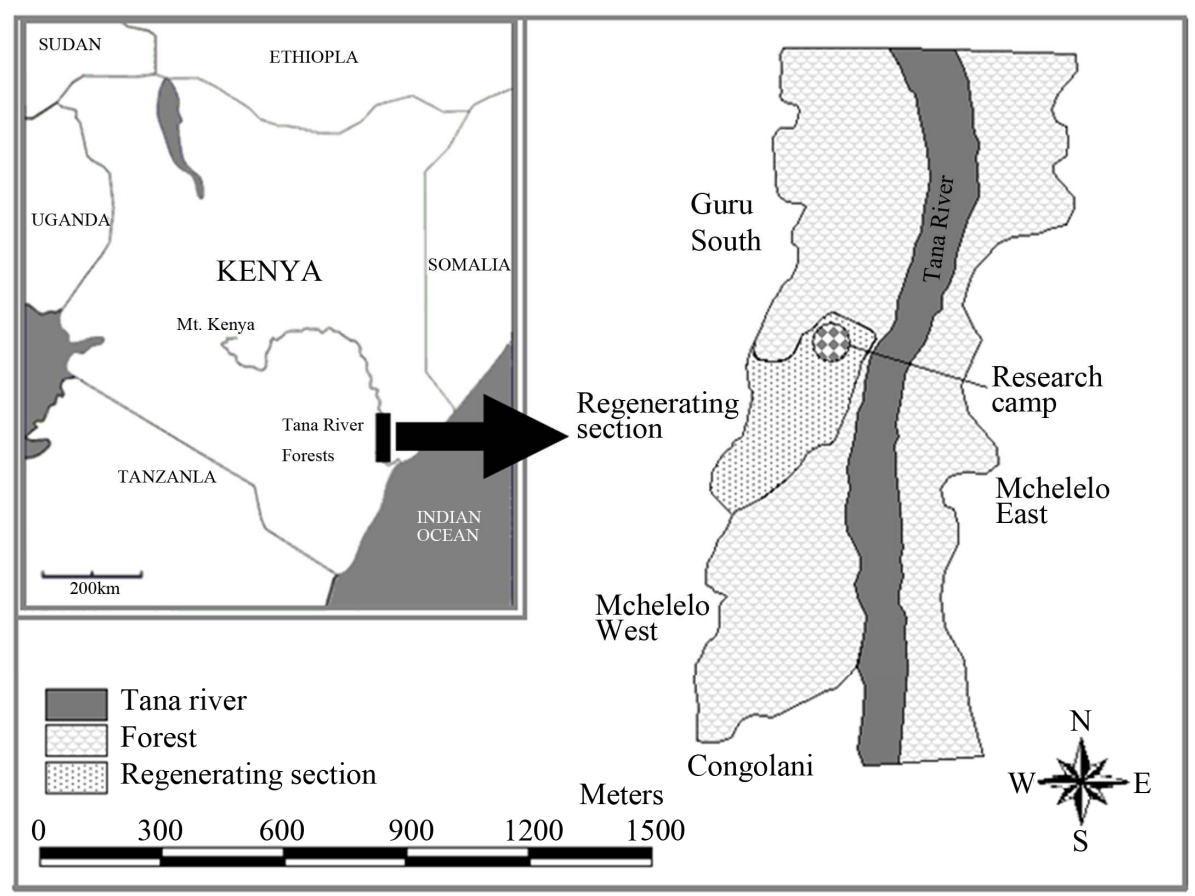

Figure 1. Map of Kenya showing the location of Tana River forests. Inset: the regenerating section of the forest, Mchelelo West, Guru South, and Congolani forests. 
days when it was impossible to make a full day follow, we compensated for the lost contact hours by following the group for extra day(s) within the same week. We employed focal animal sampling method [31] to record the frequency and handling of different food items in the mangabeys diet. Focal contacts with individuals lasted for the duration of a single eating event i.e. handling time. In detail, we observed four behaviors and their consequences on seed dispersal: 1) typical frugivory, i.e. eating pulp from fleshy-fruits and swallowing seeds most likely intact (as confirmed during random fecal analyses, i.e. checking if seeds were intact or cracked or fragmented; 2) seed spitting of basically intact seeds after removal of the pulp (as commonly observed for fruits that were held in cheek pouches); 3) seed eating (direct intended utilization) of seeds without pulp from dry-non-fleshy fruits (as confirmed during random fecal analyses); 4) seed dropping of large, hard intact seeds without entire ingestion after complete or partial removal of the pulp.

\subsection{Quantitative and Qualitative Fecal Analysis}

We recorded all incidents of defecation observed opportunistically during the follows and collected at least one fecal clump (Mean \pm SE: $1.4 \pm 0.09, \mathrm{n}=68$ ) each day for laboratory analysis to identify the species of trees for the seeds it contained. Each of the collected fecal clumps was independently strained using $250-\mu \mathrm{m}$ sieves and tap water to separate the seeds from the fecal matter. The $250-\mu \mathrm{m}$ sieves can retain fragmented seeds as well as small Ficus seeds. The extracted seeds were sun dried between filter papers, identified to species level, counted, and their diameter measured using vernier calipers. For seeds less than $1 \mathrm{~mm}$ in diameter and difficult to count due to large numbers, we used relative scores (few: $\sim 1$ 50, many: $\sim 50$ - 100, numerous: $\sim 100$ seeds) to estimate their number in a fecal clump. We then examined the extracted seeds under a dissecting microscope. All the split seeds, those with cracks and/or teeth marks were categorized as destroyed while the rest were classified as intact. Completely fragmented seeds were not counted, but the presence of fragments in the fecal clumps confirmed that the ingested seeds have been eaten and thus predated. In total, we analyzed 68 fecal clamps in the lab.

\subsection{POST-Dispersal Fate of Seeds}

To determine whether seeds that have passed through the Mangebeys gut can germinate, we placed 55 fecal clumps on the forest floor in a way to mimic natural dung deposition and used flagging tape to mark the exact location of each clump. One month after the onset of the rainy season (between April and May 2008), we counted all seedlings that germinated within a $7 \mathrm{~cm}$ radius of the location of the clump. Our focus for this experiment was to examine whether seeds contained in the mangabeys' dung could germinate under natural conditions, hence we did not attempt to exhaustively determine post-dispersal fate of the seeds. We did not determine germination percentage for two reasons: 1) dung beetles moved seeds along with fecal matter from the original deposition sites and; 2) a period of one month during which we monitored the dung wasn't adequate for all seeds to germinate.

\subsection{Seedling Survey}

For each day that we followed the mangabeys, we identified the trees used as sleeping site. For each sleeping site, we established a respective control site. A control site was an area with a similar species composition, canopy cover and tree height structure as the selected sleeping site, at a distance of at least $50 \mathrm{~m}$ from any known sleeping site including those identified in a previous study [32]. At each survey site, we delineated an area of $14 \times 14 \mathrm{~m}$ and divided it into $2 \times 2 \mathrm{~m}$ grids. We identified and counted all seedlings and saplings less than one meter tall in every second $2 \times 2 \mathrm{~m}$ quadrat to give a total of 15 quadrats sampled per site.

We used random effects model, with each site as a block and the $2 \times 2 \mathrm{~m}$ quadrats as the replicates, to test for differences in seedling/sapling density between sleeping sites and control sites. We also compared Shannon Wiener diversity indices for each sleeping site with the respective control site.

\subsection{Seasonal Fruit Availability, Food Choice and Seed Predation}

We assessed the phenological state of 112 individual plants in 28 species from December 2007 to April 2009. We estimated fruit load fortnightly using relative scores of 1 to 5 (where $0=$ no fruits, $1=1 \%-20 \%, 2=21 \%$ $40 \%, 3=41 \%-60 \%, 4=61 \%-80 \%$, and $5=81 \%-$ $100 \%$ of the possible maximum fruiting load). We averaged the scores across all trees to arrive at a monthly fruit index and compared this with the proportion of feeding events recorded for fruits, seeds and 'other items' in the mangabey's diet (see 2.2).

\subsection{Ranging Behavior}

We followed the Mangabeys and recorded the location of the group after every 30 minutes using a handheld GPS. We used straight line distance method [34] to estimate the distance moved by the group daily. The straight line distance method involves summing up straight line distances between successive locations used by the group. We used Fixed Kernel method [35] to calculate the group's home range and to generate a utilization distribu- 
tion (UD) map to highlight the probability of the group being found at any point in the home range. This method constructs regions (kernels) around each point location containing equal likelihood of animal's presence. The width of the kernel depends on the smoothing parameter used. In this case we used Least Squares Cross Validation [36] as the smoothing parameter. Areas with 50\% kernels were regarded as the core areas while areas with 95\% kernels were the range area. These analyses were done using Biotas software Version 2.0a 3.7 (Ecological Software Solutions, Florida, USA) and Animal Movement Extension 2.0 for ArcView.

\section{RESULTS}

\subsection{Fruit Handling Behavior}

We observed the mangabeys for a total of 528 contact hours during which we recorded 2946 feeding events. Fruits (obtained from a total 40 plant species) constituted $57 \%$ of these feeding events followed by $25 \%$ seeds (from 4 plant species). Other food items, which constituted $18 \%$ of the recorded feeding events, were invertebrates, leaves, stems and flowers. We recorded four main fruit and seed handling behaviors among the mangabeys in the following descending order: 1) swallowing fruits and later defecating seeds; 2) processing fruits in cheek pouches and spitting seeds; 3) Picking of dry seeds of non-fleshy fruits and seed eating; and 4) processing the fruit outside the mouth (ingesting only the pulp) and later dropping the seeds or half eaten fruit.

Generally, small fruits (less than $5 \mathrm{~mm}$ in diameter) from trees like Rinorea elliptica, Ziziphus pubescens and Rauvolvia mombasiana were swallowed together with the seeds while medium sized fruits $(5-15 \mathrm{~mm})$ like Sorindeia madagascariensis, Phoenix reclinata, Mimu- sops fruticosa and Drypetes natalensis had their seeds dropped, spit, eaten or swallowed (as confirmed from fecal analysis) after the pulp was removed. Large fruits (over $15 \mathrm{~mm}$ ) like Borassus aethiopum and Hyphaene compressa (ripe fruits) were dropped under or away from the parent tree after the pulp was partially or completely removed. The seeds of Acacia robusta and Alangium salviifolium, which are contained in non-fleshy fruits (pods), were obviously eaten themselves since; 1) we could frequently observe that only the seeds were ingested but not the fruit; 2) respectively non-fleshy fruits had probably nothing else to offer other than the seeds themselves; and 3) fecal analyses confirmed presence of fragmented seeds. Only a small proportion of seeds enclosed in fleshy fruits were destroyed. Such included, 1) Hyphaene compressa seeds; when the mangabeys opened unripe fruits to drink the liquid endosperm or when they uprooted germinating seedlings to eat the hypocotyls; and 2) Phoenix reclinata seeds; when the mangabeys collected the seeds on the forest floor during periods of fruit scarcity (see 3.5).

\subsection{Quantitative and Qualitative Fecal Analysis}

We recorded a total of 123 incidents of defecation during the follows. Ninety six percent of the sixty eight fecal clumps that we analyzed in the lab contained seeds. Ficus sycomorus seeds were the most common and they were retrieved from $44 \%$ of the fecal clumps. We extracted a total of 1500 seeds belonging to 11 tree species; excluding Ficus sycomorus seeds which were not counted because they were small in size $(<1 \mathrm{~mm})$ and occurred in large numbers (Table 1). On average, each fecal clump contained 22 large seeds $(>1 \mathrm{~mm})$, and 99\%

Table 1. Plant species, fruit type, number of intact seeds, and number of seedlings that germinated after one month of rain. Note: seed size alone is not an indicator for the condition and almost all seeds of fleshy fruits were intact. Only small soft seeds of Ziziphus pubescens were physically damaged to a very minor extent (as far as the fragments could be still found).

\begin{tabular}{|c|c|c|c|c|c|c|}
\hline Plant species & Fruit type & $\begin{array}{l}\text { Diameter in mm } \\
(\text { mean } \pm \mathrm{SE})\end{array}$ & $\begin{array}{c}\% \\
\text { Intact }\end{array}$ & $\begin{array}{l}\text { Total number of seeds } \\
\text { extracted from dung }\end{array}$ & $\begin{array}{c}\text { Number of } \\
\text { seedlings }\end{array}$ & Life form \\
\hline Acacia robusta Burch & Dry & $7.8 \pm 0.26$ & 0 & Fragments & - & Canopy \\
\hline Alangium salviifolium Wangerin & Dry & $13.1 \pm 0.67$ & 0 & Fragments & - & Sub-canopy \\
\hline Chytranthus obliquinervis Engl. & Fleshy & $9.2 \pm 0.18$ & 100 & 18 & 8 & Sub-canopy \\
\hline Drypetes natalensis (Harv.) Hutch. & Fleshy & $11.5 \pm 0.28$ & 100 & 13 & 3 & Sub-canopy \\
\hline Ficus sycomorus L. ${ }^{\mathrm{a}}$ & Fleshy & $<1 \mathrm{~mm}$ & $100^{\mathrm{a}}$ & Numerous & 6 & Canopy \\
\hline Grewia densa K. Schum. & Fleshy & $4.1 \pm 0.20$ & 100 & 7 & 5 & Sub-canopy \\
\hline Oncoba spinosa Forssk. & Fleshy & $3.9 \pm 0.28$ & 100 & 22 & 6 & Sub-canopy \\
\hline Phoenix reclinata Jacq. & Fleshy & $7.9 \pm 0.14$ & 100 & 96 & 16 & Sub-canopy \\
\hline Polysphaeria multiflora Hiern & Fleshy & $4.1 \pm 0.12$ & 100 & 28 & 28 & Sub-canopy \\
\hline Rauvolfia mombasiana Stapf & Fleshy & $4.2 \pm 0.07$ & 100 & 17 & 9 & Sub-canopy \\
\hline Sorindeia madagascariensis Thou. & Fleshy & $10.4 \pm 0.14$ & 100 & 18 & 1 & Canopy \\
\hline
\end{tabular}

${ }^{\mathrm{a}}$ Samples of ten seeds drawn from 29 fecal clump showed no signs of physical damage therefore all Ficus sycomorus seeds were assumed to be intact. 
of the extracted seeds had no observable signs of physical damage (Table 1). However, the mangabeys completely destroyed probably almost all seeds of Acacia robusta and Alangium salviifolium; for these plant species we only found seed fragments in the feces and their diaspores were not dispersed by other means as far as observed. Predation of Ziziphus pubescens and Phoenix reclinata seeds was much lower (probably $10 \%$ ) than the effectively dispersed seeds, and occurred mainly when dry seeds were collected from the forest floor during periods of fruit shortage.

\subsection{Post-Dispersal Fate of Seeds}

Dung beetles buried $56 \%(n=55)$ of the experimental fecal clumps within one day after deposition, as evidenced by presence of fresh burrows. The rest (44\%) were probably rolled away and buried elsewhere or removed by other secondary disperser or predators. At least one seedling germinated from $55 \%$ of 55 fecal clumps that we monitored. Most seedlings that germinated were for Ziziphus pubescens (Table 1).

\subsection{Seedling Survey}

Three sleeping sites were used for 42 days ( $~ 88 \%)$ out of the total 48 observation days. The first site, Site 1 was located in Guru South forest, and the mangabey group used it for $25 \%$ of the observation days. Site 1 was dominated by Sorindeia madagascariensis. Other canopy trees included Garcinia livingstonei, Acacia robusta, and Hyphaene compressa. The dominant sub-canopy tree was Pavetta sphaerobotrys. The second site, Site 2, was located in Mchelelo West forest. The mangabeys used for sleeping by the mangabeys for $33 \%$ of the observation days. It was dominated by Ficus sycomorus. Other canopy trees at this site included Sorindeia madagascariensis, and Pachystela msolo. The dominant sub-canopy tree was Phoenix reclinata. This area had also been identified as a sleeping site for the same group on mangabeys in a previous study [32]. The mangabeys slept on the third site, Site 3 , for $19 \%$ of the observation time. It was located in the regenerating section of the forest between Mchelelo West and Guru South. The site was mainly a secondary forest dominated by Hyphaene compressa and Phoenix reclinata. Canopy trees included Garcinia livingstonei, Diospyros mespiliformis and Ficus sycomorus. A detailed description of selection of sleeping sites by the mangabeys is provided by [32].

Sleeping sites had more seedlings and saplings (64\%; $\mathrm{n}=5026$ ) that control sites (Figure 2). These difference in seedling and sapling density between sleeping site and control sites was significant $\left(\mathrm{F}_{2,84}=10.9 ; \mathrm{P}=0.02\right)$. Shannon Wiener index of plant species diversity was higher in sleeping Sites 1 and 2 than in their respective control sites but lower in sleeping Site 3 (Figure 3)The most abundant seedlings were of Ziziphus pubescens, constituting $25 \%$ of the total counts, followed by Sorindeia madagascariensis (15\%).

\subsection{Seasonal Fruit Availability, Food Choice and Seed Predation}

Fruit availability peaked in January and this was followed by a steady decline up to April (Figure 4). The mangabeys respoded decline in fruits by increasing consumption of seeds and other dietary items.

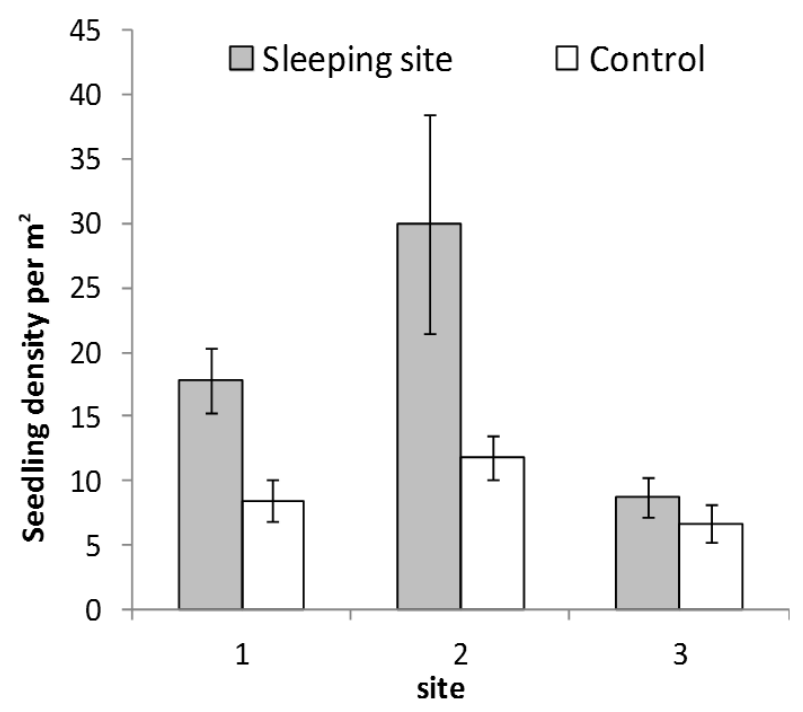

Figure 2. Mean seedling density at sleeping sites and respecttive control sites of 40 plant species dispersed by the mangabeys (error bars represent standard error).

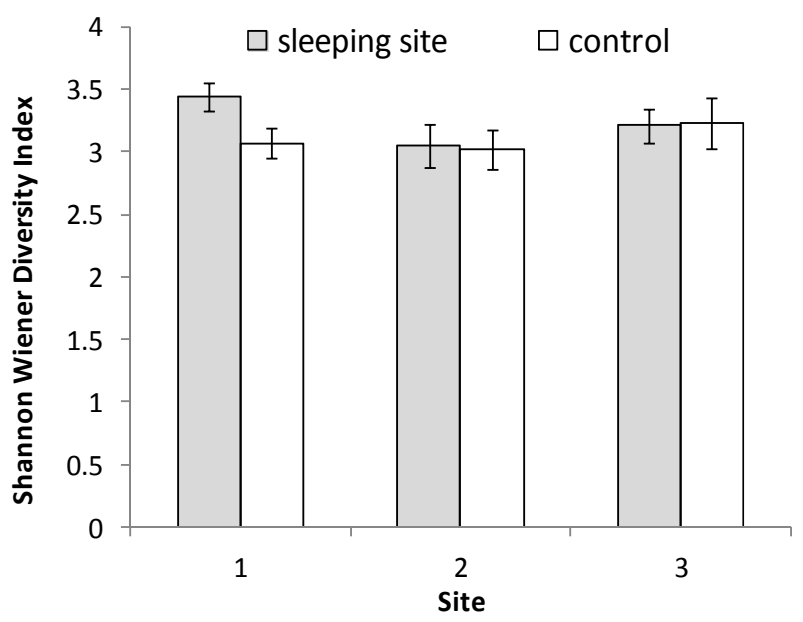

Figure 3. Plant species diversity (seedling and sapling) at sleeping sites and respective control sites. Shannon Wiener index of species diversity was higher in sleeping Sites 1 and 2 than the respective control sites but lower in sleeping Site 3 . 


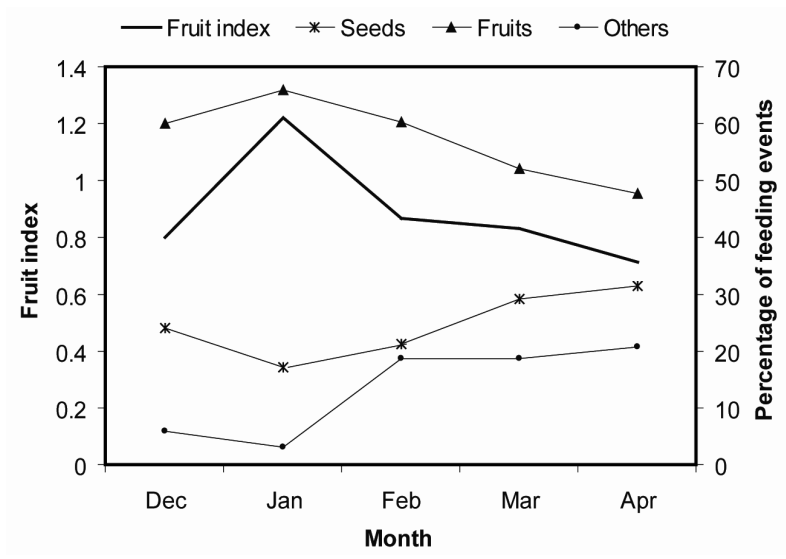

Figure 4. Variations in fruit availability and composition of different food items in the mangabeys diet. The managebeys consume more seeds (seed predation) when fruits are scarce.

\subsection{Ranging Behavior}

The mangabeys group used a home range of 35.5 ha during the four months study and covered an average of $1493.9 \pm 235.9 \mathrm{~m}$ per day. The mangabeys spent $75 \%$ of their time in the Guru South forest, $13 \%$ in the Mchelelo West forest, $11 \%$ in a section of regenerating forest between Guru South and Mchelelo West, and 1\% in Congolani forest (Figure 5(a)). The group crossed between Mchelelo West and Guru South forests, through the regenerating section, at least once every two days. Out of the 123 records of defecation, $23 \%$ occurred at the regenerating section of the forest (Figure 5(b)).

\section{DISCUSSION}

Our findings clearly show that Tana River mangabeys play an important role in dispersing seeds for some of their dietary plants. Our findings contradict previous studies which regarded Tana River mangabeys generally as seed predators $[20,24,37]$. While some earlier studies reported more seed predation than frugivory by the mangabeys [20,22], we observed more frugivory than seed predation. Predation was only recorded in specific plant species, most of which had non-fleshy fruits.

The four main fruit and seed processing behaviors documented in this study have different implications for seed dispersal and its effectiveness. 1) Seed swallowing, common for fleshy small fruits $(<5 \mathrm{~mm}$ diameter), enables long-distance seed dispersal. Frugivory and endozoochory are common in these Mangabeys, thus they are predominantly efficient seed dispersers.

Swallowed seeds are more likely to be dispersed farthest from the parent tree, escape potential competition and distance/density mortality and contribute best to colonization [33]. Dispersal distance depends on many other factors such as retention time in the gut, food availability and movement patterns [38]. Endozoochory

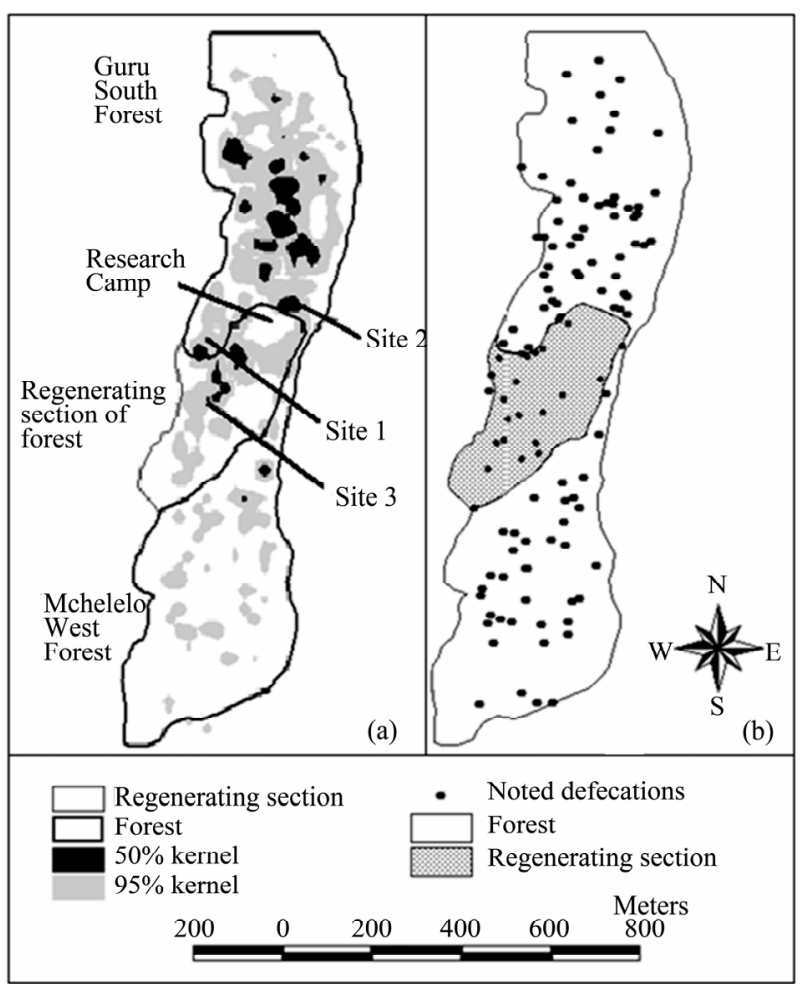

Figure 5. Ranging behavior of Tana River Mangabeys (a) range utilization distribution map; (b) spatial pattern of recorded defecations during four months. The mangabeys spent $11 \%$ of the total observation time and also defecated in the regenerating section of the forest.

may reduce latency period to germination $[10,39,40]$ although the effects for plant regeneration are more complex than any potential acceleration or delay of seed germination $[16,41]$. 2) For spit, non-swallowed seeds, cheek processing removes pulp which could otherwise encourage seed predation and fungal pathogen attack [42]. The threshold for swallowing or spitting is influenced by the size of the seeds [43] and physical characteristics of the fruits such as slipperiness of the pulp [44]. 3 ) Intended direct seed eating (and hence seed destructtion/predation), as observed for Accacia robusta and Alangium salviifolium with dry fruits, may reduce the number of available propagules, but usually does not endanger plants. This is mainly because most of the plants have adopted other mechanisms for their seed dispersal despite common seed predation[16]. 4) The here also observed fruit handling behavior involving processing fruits outside the mouth and dropping the seeds or half eaten fruits was common for but usually restricted to large-seeded fruits $(>15 \mathrm{~mm})$ such as $B o-$ rassus aethiopum and Hyphaene compressa. This mode of dispersal is as rare as species with large-seeded fruits and most dispersers would rather eat smaller fruits at the parent tree and disperse the seeds than move around with the fruits and drop the seeds near by the parent plant. 
There have been observed significant variations across the studies in the proportion of fruits to seeds handled by the mangabeys'. These variations, appear largely dictated by seasonal changes in food availability [29], as observed during our study. Although our four months study does not permit detailed evaluation of the response of the mangabeys to seasonal changes in fruit availability, it does however show consistent inverse relationship between seed predation and fruit index. Future studies can benefit from exploring this relationship in more details and over extended periods of time. An earlier study suggested that Tana River mangabeys increase their consumption of seeds from non-fleshy fruits when fleshy fruits are scarce [26], hence seeds can be seen as fallback food items. This is expected, considering that seeds may have high level of toxins $[5,14,45,46]$ and are relatively difficult to handle [47]. To a minor extent, the qualitative efficiency of mangabeys as seed dispersers or seed predators may specifically fluctuate with seasonality in fruit abundance as reported for Phoenix reclinata. However, for those few plant species whose seeds are eaten, the effectiveness of mangabeys as seed dispersers is negligible, but for the majority of the diet plants, seeds are efficiently dispersed.

The finding of this study indicates that, Tana River mangabeys increase the density of seedlings and species diversity in areas used as sleeping sites. This is demonstrated by the significant relationship between the number of days a site was used and seedling density. A similar observation has been reported in other species including howler monkeys Alouatta paliatta [48] and $A$. seniculus [49], Tamarins Saguinus fuscicollis and Saguinus mystax [50], and spider monkeys Ateles paniscus [51]. It should be noted that other factors not accounted for in this study could also have contributed to the observed pattern. For example, the same sleeping sites used by mangabeys were also used by other frugivores such as yellow baboons [32] which are known to play a major part in overall seed dispersal in other coastal forests in Kenya [16]. However, the strong positive relationship between utilization of sleeping sites and seedling density and the observed endozoochory is a strong indication that also the mangabeys play a significant role in dispersing seeds. Although increase in seedling population at sleeping sites may not necessarily benefit final regeneration, it already does increase floristic spatial heterogeneity in otherwise more homogeneous forests. This indicates that regeneration through endozoochory is generally possible at other more disturbed sites with less clumped seed deposition.

The large home range and daily ranging distance that we recorded in this study indicates that mangabeys likely disperse seeds over long distances. In addition, they also utilized a non-forested corridor as part of their core ranging areas (Figure 2) and a sleeping site (sleeping site 3 ). This is particularly advantageous to seed dispersal as it not only increases potential dispersal distance but also allows the deposition of seeds in habitat gaps. Studies elsewhere have shown that persistence of primates in fragmented habitats can facilitate regeneration especially when the primates move across forest patches and disperse seeds in habitats different from where they are ingested [52].

\subsection{Conclusion}

The behavior of Tana River mangabeys, to feed largely on fruits, to use cheek pouches and to spit and defecate viable seeds, range widely, to move between forest patches and to utilize habitat matrix are some of the qualities which render them potential dispersers of their dietary plants. Their overall contribution to the seed rain in the area is barely lowered by the albeit considerable proportion of predated but common Acacia seeds, especially during periods of food scarcity. We recommend long-term studies, which could reveal important seasonal and plant specific variations in quality and quantity of seeds dispersed by this endangered primate, as well as post-dispersal fate of seeds handled by the mangabeys. In order to understand their ecology and relative importance for the maintenance of the endangered biocoenosis, another promising line of investigation could be compareson of seed dispersal by the mangabeys with other seed dispersers in the region.

\section{ACKNOWLEDGEMENTS}

We owe gratitude to numerous people who, in their unique ways, contributed to the success of this study. We are indebted to Mustafa Lodi, Abeid Said, Jillo Hamisi, Mohamed Bwanamaka and Abio Gafo, for their warm reception and constructive input during field work. Our research assistant, Michael Morowa, deserves special appreciation. We thank the Tropical Biology Association, Mwangi Githiru, Thomas Engel, Flora Namu and two anonymous reviewers for their constructive reviews of earlier versions of this paper. We could not accomplish this work without the financial support from Critical Ecosystem Partnership Fund through its project entitled "Small Grants for Building Research Capacity among Tanzanian and Kenyan Students". This research was affiliated to the Kenya Wildlife Service (KWS) under permission granted by the Government of Kenya through the research permit No. MOST $13 / 001$.

\section{REFERENCES}

[1] Wunderle, J.M. (1997) The role of animal seed dispersal in accelerating native forest regeneration on degraded tropical lands. Forest Ecology and Management, 99, 223-235. doi:10.1016/S0378-1127(97)00208-9

[2] Stoner, K.E., Riba-Hernandez, P., Vulinec, K. and Lam- 
bert, J.E. (2007) The role of mammals in creating and modifying seedshadows in tropical forests and some possible consequences of their elimination. Biotropica, 39, 316-327. doi:10.1111/j.1744-7429.2007.00292.x

[3] Hardesty, B.D. (2011) Effectiveness of seed dispersal by ants in a neotropical tree. Integrative Zoology, 6, 222226. doi:10.1111/j.1749-4877.2011.00246.x

[4] Ganzhorn, J.U., Fietz, J., Rakotovao, E., Schwab, D. and Zinner, D. (1999) Lemurs and the regeneration of dry deciduous forest in Madagascar. Conservation Biology, 13, 794-804. doi:10.1046/j.1523-1739.1999.98245.x

[5] Lambert J.E. and Garber, P.A. (1998) Evolutionary and ecological implications of primate seed dispersal. American Journal of Primatology, 45, 9-28.

[6] Chapman C.A. and Russo, S.E. (2005) Primate seed dispersal: Linking behavioral ecology with forest community structure. Ecology, 13, 510-525.

[7] Clark, C.J., Poulsen, J.R., and Parker, V.T. (2001) The role of arboreal seed dispersal groups on the seed rain of a lowland tropical forest. Biotropica, 33, 606-620. doi:10.1111/j.1744-7429.2001.tb00219.x

[8] Culot, L., Lazo, F., Huynen, M.C., Poncin, P. and Heymann, E.W. (2010) Seasonal variation in seed dispersal by tamarins alters seed rain in a secondary rain forest. $I n$ ternational Journal of Primatology, 31, 553-569.

[9] Balcomb S.R. and Chapman, C.A. (2003) Bridging the gap: Influence of seed deposition on seedling recruitment in a primate-tree interaction. Ecological Monographs, 73, 625-642. doi:10.1890/02-4036

[10] Wrangham, R.W., Chapman, C.A. and Chapman, L.J. (1994) Seed dispersal by forest chimpanzees in Uganda. Journal of Tropical Ecology, 10, 355-368. doi:10.1017/S0266467400008026

[11] Kaplin, B.A., Munyaligoga, V. and Moermond, T.C. (1998) The influence of temporal changes in fruit availability on diet composition and seed handling in blue monkeys (cercopithecus mitis doggetti). Biotropica, 30, 56-71. doi:10.1111/j.1744-7429.1998.tb00369.x

[12] Gross-Camp, N.D., Masozera, M. and Kaplin, B.A. (2009) Chimpanzee seed dispersal quantity in a tropical montane forest of Rwanda. American Journal of Primatology, 71, 901-911. doi:10.1002/ajp.20727

[13] Chapman, C.A. (1995) Primate seed dispersal: Coevolution and conservation implications. Evolutionary Anthropology, 4, 74-82. doi:10.1002/evan.1360040303

[14] Norconk, M.A., Grafton, B.W. and Conklin-Brittain, N.L. (1998) Seed dispersal by neotropical seed predators. American Journal of Primatology, 45, 103-126. doi:10.1002/(SICI)1098-2345(1998)45:1<103::AID-AJP 8>3.0.CO;2-\#

[15] Gautierhion, A., Gautier, J.P. and Maisels, F. (1993) Seed dispersal versus seed predation-An inter-site compareson of 2 related African monkeys. Vegetation, 108, 237244.

[16] Engel, T.R. (2001) Seed Dispersal and Forest Regeneration in a Tropical Lowland Biocoenosis (Shimba Hills, Kenya). Logos, Berlin.

[17] IUCN, IUCN red list of threatened species. Gland, Swit- zerland, IUCN, 2009.

[18] Kinnaird M.F. and Obrien, T.G. (1991) Viable populations for an endangered forest primate, the Tana River crested mangabey (Cercocebus galeritus galeritus). Conservation Biology, 5, 203-213. doi:10.1111/j.1523-1739.1991.tb00125.x

[19] Homewood, K.M. (1976) Ecology and behavior of the Tana Mangabey (Cercocebus galeritus galeritus). Ph.D. Thesis, University of London, London.

[20] M. Kinnaird, (1990) Behavioral and demographic responses to habitat change by the Tana River Crested Mangabey (Cercocebus galeritus galeritus). Ph.D. Thesis, University of Florida, Gainesville, Florida,

[21] Wahungu, G.M. (1993) Resource use overlap and competition between the Tana Crested Mangabey (Cercocebus galeritus galeritus) and Yellow Baboon (Papio cynocephalus cynocephalus). M.Phil. Thesis, Moi University, Eldoret.

[22] Wieczkowski, J. (2003) Aspects of the ecological flexibility of the Tana Mangabey (Cercocebus galeritus) in its fragmented habitat, Tana River, Kenya. Ph.D. Thesis, University of Georgia, Athens.

[23] Wieczkowski, J. (2009) Brief communication: Puncture and crushing resistance scores of Tana River Mangabey (Cercocebus galeritus) diet items. American Journal of Physical Anthropology, 140, 572-577. doi:10.1002/ajpa.21132

[24] Kinnaird, M. (1992) Competition for a forest palm: Use of phoenix reclinata by human and nonhuman primates. Conservation Biology, 6, 101-107. doi:10.1046/j.1523-1739.1992.610101.x

[25] Wieczkowski, J. (2005) Examination of increased annual range of a Tana Mangabey (Cercocebus galeritus) group. American Journal of Physical Anthropology, 128, 381388. doi:10.1002/ajpa.20123

[26] Wahungu, G.M. (1998) Diet and habitat overlap in two sympatric primate species, the Tana Crested Mangabey (Cercocebus galeritus) and Yellow Baboon (Papio cynocephalus). Af-rican Journal of Ecology, 36, 159-173. doi:10.1046/j.1365-2028.1998.00120.x

[27] Wieczkowski, J. (2010) Tana River Mangabey use of nonforest areas: Functional connectivity in a fragmented landscape in Kenya. Biotropica, 42, 598-604. doi:10.1111/j.1744-7429.2010.00627.x

[28] Marsh, C.W. (1978) Ecology and social organization of the Tana River Red Colobus (Colobus badius rufomitratus). Ph.D. Thesis, University of Bristol, Bristol.

[29] Wieczkowski, J. and Kinnaird, M. (2008) Shifting forest composition and primate diets: A 13-year comparison of the Tana River Mangabey and its habitat. American Journal of Primatology, 70, 339-348. doi:10.1002/ajp.20495

[30] Medley, K.E. (1992) Patterns of forest diversity along the Tana River, Kenya. Journal of Tropical Ecology, 8, 353371. doi:10.1017/S0266467400006684

[31] Altmann, J. (1974) Observational study of behavior-Sampling Methods. Behaviour, 49, 227-267. doi:10.1163/156853974X00534

[32] Wahungu, G.M. (2001) Common use of sleeping sites by 
two primate species in Tana River, Kenya. African Journal of Ecology, 39, 18-23. doi:10.1111/j.1365-2028.2001.00263.x

[33] Howe, H.F. and Smallwood, J. (1982) Ecology of seed dispersal. Annual Review of Ecology, Evolution, and Systematics, 13, 201-228.

doi:10.1146/annurev.es.13.110182.001221

[34] Isbell, L.A., Pruetz, J.D., Nzuma, B.M. and Young, T.P. (1999) Comparing measures of travel distances in primates: Methodological considerations and socioecological implications. American Journal of Primatology, 48, 87-98.

doi:10.1002/(SICI)1098-2345(1999)48:2<87::AID-AJP1 $>3.0 . \mathrm{CO} ; 2-\mathrm{G}$

[35] Worton, B.J. (1989) Kernel methods for estimating the utilization distribution in home-range studies. Ecology, 70, 164-168. doi: $10.2307 / 1938423$

[36] Seaman D.E. and Powell, R.A. (1996) An evaluation of the accuracy of kernel density estimators for home range analysis. Ecology, 77, 2075-2085. doi:10.2307/2265701

[37] Wieczkowski, J. (2011) The value of measuring food availability on the ground for a terrestrial seed predator, the Tana River Mangabey (Cercocebus galeritus) of Kenya. American Journal of Primatology, 73, 105-105.

[38] Stevenson, P.R. (2000) Seed dispersal by Woolly Monkeys (Lagothrix lagothricha) at Tinigua National Park, Colombia: Dispersal distance, germination rates, and dispersal quantity. American Journal of Primatology, 50, 275-289.

doi:10.1002/(SICI)1098-2345(200004)50:4<275::AID-AJ P4>3.3.CO;2-B

[39] Martins, M.M. (2006) Comparative seed dispersal effecttiveness of sympatric Alouatta guariba and Brachyteles arachnoides in southeastern Brazil. Biotropica, 38, 57-63.

[40] Stevenson, P.R., Castellanos, M.C., Pizarro, J.C. and Garavito, M. (2002) Effects of seed dispersal by three ateline monkey species on seed germination at Tinigua National Park, Colombia. International Journal of Primatology, 23, 1187-1204. doi:10.1023/A:1021118618936

[41] Traveset A. and Verdú, M.A (2002) Meta-analysis of gut treatment on seed germination. In: Levey, D.J., Galetti, M. and Silva, W.R. Eds., Frugivores and Seed Dispersal: Ecological, Evolutionary and Conservation Issues, CAB International, Wallingford, pp. 339-350.

[42] Lambert, J.E. (2001) Red-Tailed Guenons (Cercopithecus ascanius) and Strychnos mitis: Evidence for plant benefits beyond seed dispersal. International Journal of Primatology, 22, 189-201. doi:10.1023/A:1005667313906
[43] Corlett, R.T. (1998) Frugivory and seed dispersal by vertebrates in the oriental (indomalayan) region. Biological Reviews of the Cambridge Philosophical Society, 73, 413448. doi:10.1017/S0006323198005234

[44] Utzurrum R.C.B. and Heideman, P.D. (1991) Differential ingestion of viable vs nonviable ficus seeds by fruit bats. Biotropica, 23, 311-312. doi:10.2307/2388211

[45] Janson C.H. and Chapman, C.A. (1999) Resources and primate community structure. In: Fleagle, J.G., Janson, C.H. and Reed, K.E., Eds. Primate Communities, Cambridge University Press, New York, 237-267. doi:10.1017/CBO9780511542381.015

[46] Corlett R.T. and Lucas, P.W. (1990) Alternative seedhandling strategies in primates - Seed-spitting by LongTailed Macaques (Macaca-fascicularis). Oecologia, 82, 166-171. doi:10.1007/BF00323531

[47] Lambert, J.E., Chapman, C.A., Wrangham, R.W. and Conklin-Brittain, N.L. (2004) Hardness of cercopithecine foods: Implications for the critical function of enamel thickness in exploiting fallback foods. American Journal of Physical Anthropology, 125, 363-368. doi:10.1002/ajpa.10403

[48] Anzures-Dadda, A., Andresen, E., Luisa-Martinez, M. and Manson, R.H. (2011) Absence of Howlers (Alouatta palliata) influences tree seedling densities in tropical rain forest fragments in southern Mexico. International Journal of Primatology, 32, 634-651. doi:10.1007/s10764-011-9492-0

[49] Julliot, C. (1997) Impact of seed dispersal of Red Howler Monkeys (Alouatta seniculus) on the seedling population in the understorey of tropical rain forest. Journal of Ecology, 85, 431-440. doi:10.2307/2960567

[50] Lazo, F., Culot, L., Huynen, M.C. and Heymann, E.W. (2011) Effect of resting patterns of tamarins (Saguinus fuscicollis and Saguinus mystax) on the spatial distribution of seeds and seedling recruitment. International Journal of Primatology, 32, 223-237. doi:10.1007/s10764-010-9463-x

[51] Russo S.E. and Augspurger, C.K. (2004) Aggregated seed dispersal by spider monkeys limits recruitment to Clumped Patterns in Virola calophylla. Ecology Letters, 7, 10581067. doi:10.1111/j.1461-0248.2004.00668.x

[52] Oliveira A.C.M. and Ferrari, S.F. (2000) Seed dispersal by Black-Handed Tamarins, Saguinus midas niger (Callitrichinae, Primates): Implications for the regeneration of degraded forest habitats in eastern Amazonia. Journal of Tropical Ecology, 16, 709-716. doi:10.1017/S0266467400001668 